\title{
Possibility of stevia (Stevia rebaudiana B.) production in Hungary
}

\author{
Takácsné Hájos, M., Rubóczki, T. \& Kiss, A. \\ University of Debrecen, Faculty of the Agricultural and Food Sciences \\ and Environmental Management, Horticulture Department, \\ H-4032 Debrecen, Böszörményi Street 138. \\ E-mail: hajos@agr.unideb.hu
}

\begin{abstract}
Summary: Artificial sweeteners have harmful effect on human health, so it is great interested in stevia extract. Our experiment was aimed to show the possibility of inland production of stevia. Different plastic mulches were used (black and white) on raised bed and were compared to uncovered (control) plots for yield and state of health of plants. Furthermore we evaluated the depth of cuttings (low cutting until the $6^{\text {th }}$ double leaf; normal cutting until the upper $1 / 3$ of the plant) on the yield depending on the covering method. The plants were transplanted on 9 of May, 2014 on raised bed, 3 rows on it, with $33 \times 25 \mathrm{~cm}$ spacing. According to our results, the black plastic mulch produced the highest yield, which can be explained by suppressing effect on weeds, furthermore it kept the soil warm, moist and protected the lower leaves from soil wetness. But, the white sheet mulch could not eliminate weeds around the plants. The total biomass on the black plastic sheet covered plots was the highest, nearly 1000 g pro plant by low cutting. On the control plots the fungi infection reached about $25-30 \%$, which caused leaf falling of plants, decreasing of yield by the end of vegetation period. To summarise, stevia production is possible in Hungary, but it is important to pay attention to the balanced soil moisture and low humidity in the leaf area. It is suggested to cover the soil with plastic sheet or organic materials, such as bark and chippings.
\end{abstract}

Keywords: stevia, black / white plastic sheet, leaf weight, covering, raised bed, fungi infection

\section{Introduction}

Several documents show that about $8 \%$ of the global population struggle with diabetes. In fact, diabetes brings about other problems such as obesity which can cause not only esthetical but also health care difficulties. As a result, artificial sweeteners like aspartame have been developed with the risk of causing a harmful effect on human health (Swithers \& Davidson, 2008).

On $11^{\text {th }}$ of November 2011 the regulation of European Commission (1131/2011/EU) has permitted the use of steviolglycosides in food industry. According to this regulation several stevia extract and products sweetened with stevia are appeared in food stores and bio-shops.

The stevia (Stevia rebaudiana B.) is an indigenous plant in South America. Its distribution ranges from Southern United States and North Eastern Paraguay to South Eastern Brazil through Central America (Soejaro et al., 1982). It is a member of Asteraceae. Some of the active constituents of the leaves are 300 times sweeter than sugar. The powder made of dried leaves, which is 30 times sweeter than sugar, has been used by Paraguayan indigenous people from several decades (Geuns et al., 2003).

Nowadays the largest production is located in China (20 thousand ha), Japan and South Korea. After the EU declaration, the growing of this species is going to be very perspective in Europe and Hungary as well and probably it would be possible to change the great import of stevia to local source production.

The speciality of this plant owes to its glycoside components which do not increase the steviol content in the blood and this metabolite is recirculated by entero-hepatic way (Yamada et al., 1985). In fact, it can be used safely because it does not increase the blood-sugar and insulin level. It is a zero and low-calorie sweetener which can play a useful role in healthy, balanced diet and help patients to control their calorie intake along with an alleviation of the global burden. Besides, stevia does not have any influence in the glycaemic index and it does not produce a toxic effect in the organism. In summary, this natural sweetener can be used safely in everyday life for long periods for sweetening drinks and foods.

Morphological features - stevia's feeder root is extensive, near to the soil surface. The root system is sensitive to excessive moisture, thereby irrigation must be strictly monitored. During summer time, irrigation with smaller doses brings about the best results. The mulch around the plant can protect the shallow feeder root from drying out. Without pruning, the plant can even reach the $120 \mathrm{~cm}$ height, whereas the population of plants with a frequent cutting of leaves are about $30-50 \mathrm{~cm}$.

The leaves are sessile, approx. $5 \mathrm{~cm}$ long and $2 \mathrm{~cm}$ wide, opposite, lanceolate in shape and have serrated leaf margin (Carneiro, 2007). The stem is brittle and densely covered 
with gland cell. Glandular trichrome are in hollows of leaf blades (Bondarev et al., 2010). The tubular flowers are white in colour. The seed is achene with feathery pappus, 2-3 mm long (Kinghorn et al., 1982). The germination ability is rather low, so the propagation is possible mainly with vegetative method. Disadvantage of generative propagation is connected to greatly varying in stevioside levels compare to vegetative method (Jain et al., 2014).

Environmental conditions: The ideal temperature range is between $15{ }^{\circ} \mathrm{C}$ to $30{ }^{\circ} \mathrm{C}$; water requirements are about $1800 \mathrm{~mm}$ yearly. The right combination of sunlight, temperature and water supply can determinate the quality and quantity of steviol-glycosides content in the plant.

Stevia requires warm condition due to its origin in South America. Therefore, only one-year production can be carried out under our climate. The winter storing is possible in heated places. During the growing period the optimal temperature is between $15-30{ }^{\circ} \mathrm{C}$, but in autumn time plants can tolerate even $0-(-3){ }^{\circ} \mathrm{C}$ for some days.

The other important environmental factor is light intensity. Stevia needs warm, humid and sunny climate.

A $60 \%$ decreasing of light intensity (shadow) can cause negative effect on biomass production and leaf yield. In fact, long days increase the stevioside content up to $50 \%$ as compared to plants grown under short days (Metivier and Viana, 1979). The stevia requirement of water is not so high, but it is important to ensure a balanced soil humidity. This plant can be affected by leaf spot disease caused by Alternaria alternate due to an excess in water supply and high soil moisture (Surjit et al., 2012). The further fungi disease is Septoria steviae. After the disease appears, the leaves quickly become necrotic and the plant often drops off them. The disease can be progressed upward during the growing season. The optimal conditions of infection were found from $20^{\circ} \mathrm{C}$ to $25^{\circ} \mathrm{C}$ (Reeleder, 1999).

The best soil type for the production is sandy loam or loam. This plant is sensitive to high salt content in the soil, recommended mildly acid soil ( $\mathrm{pH}$ 6.5). In addition, stevia plants can be propagated from cutting, seeds or tissue culture. As the seed germination is very poor and seedlings are very slow to establish (Jain et al., 2014).

In Hungary the climatic conditions are not adequate for flowering and full ripening of seeds, consequently the seeds are usable only partially for propagation. Mainly vegetative propagation is used, so it can eliminate the difficulties of germination and starting improvement. In fact, the great effort of vegetative propagation is the ability to save the good and favourable properties of mother population. It is known that stevia has the typical unfavourable aftertaste for the customers which is a decisive factor of preference. In order to reduce its special taste and develop an approving one, a vegetative propagation must be carried out.

Regarding to genetics, strong variability was observed among different cultivars with respect to leaf yield, rebaudioside content and the ratio of rebaudioside to stevioside (Shizhen, 1995).

\section{Materials and methods}

The experiment was carried out in the Horticultural Demonstration Garden of the Faculty of Agricultural and Food Science and Environmental Management, University of Debrecen. The main aim was to evaluate the effect of mulching in agronomic properties. Transplanting was done on 9 of May, 2014 on raised bed (3 rows on it), the row distance was $33 \mathrm{~cm}$ and $25 \mathrm{~cm}$ between the plants (12 plants/ $\mathrm{m}^{2}$ ). Black and white plastic sheets were used for covering the growing surface, depending on the treatment. The control plots were uncovered.

During the experiment we tried to evaluate the depths of cutting - low cutting (L) until the $6^{\text {th }}$ double leaf; normal cutting $(\mathrm{N})$ until the upper one third of the plant.

The measurement was carried on:

- Ratio of leaf weight in total biomass (\%)

- Raw material $\left(\mathrm{g} / \mathrm{m}^{2}\right)$ - depending on the covering and the cutting method in different time of harvesting

- $\quad$ Rate of fungi disease (\%) by different treatments evaluation of occurring the ratio of infected plants of plots

- Dry leaf weight $\left(\mathrm{g} / \mathrm{m}^{2}\right)$ by different treatments

\section{Results}

The leaf weight ratio compare to total biomass is shown on the Figure 1. At the first cutting, the white sheet covering and normal cutting (upper one third) produced the highest leaf ratio $(78.95 \%)$, it was followed by the yield of black sheet covering (73.68-74.17\%), comparing to uncovered. Regarding to control plots (uncovered) we measured higher results $(67.25 \%)$ by low cutting (L). It can be explained by the lower cutting which promoted the renewing of the plants. This favourable effect was not detected at the end of vegetation period, because the greater humidity near the soil surface increased the fungi infection of lower leaves. This unfavourable effect was detected mainly on the third cutting in autumn time.

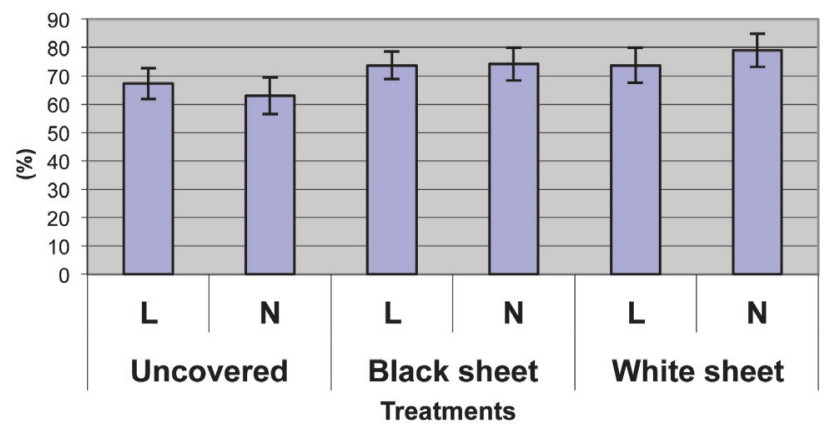

Figure 1. Leaf weight in the ratio of total biomass production (\%) by the first cutting (L-low cutting, N-normal cutting) 
The data of raw weight of different cuttings are shown on Figure 2. The highest raw weight was measured on the black sheet treatment by every cutting. It can be explained by the better health condition of plants on these plots, because the fungi infection was less than the other treatments (Fig. 3). The white sheet covering could not bring about good results, because under this sheet, intensive weed proliferation was detected.

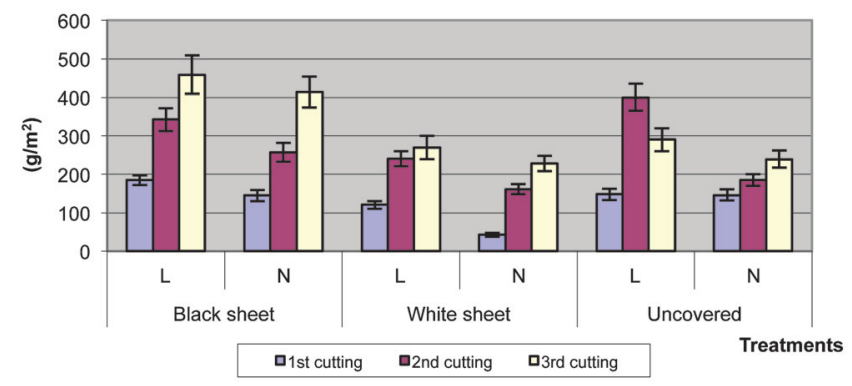

Figure 2. Evaluation of raw weight $\left(\mathrm{g} / \mathrm{m}^{2}\right)$ by different treatments

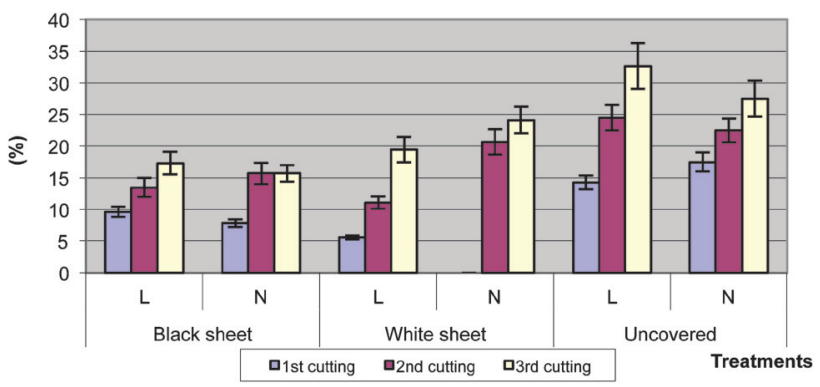

Figure 3. Rate of fungi infection (\%) by different treatments

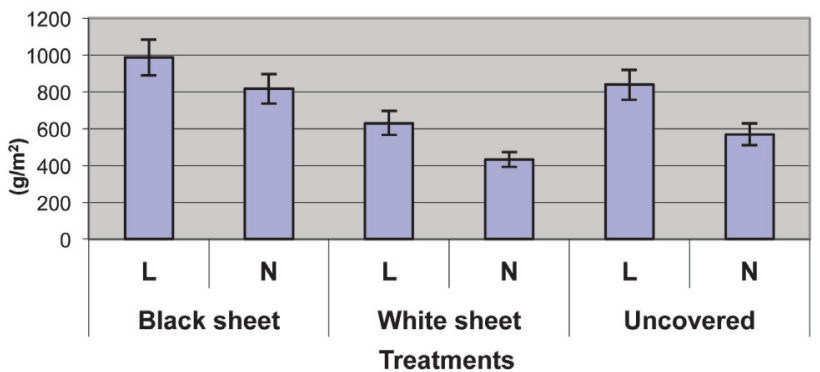

Figure 4. Total fresh biomass yield $\left(\mathrm{g} / \mathrm{m}^{2}\right)$ during the vegetation period

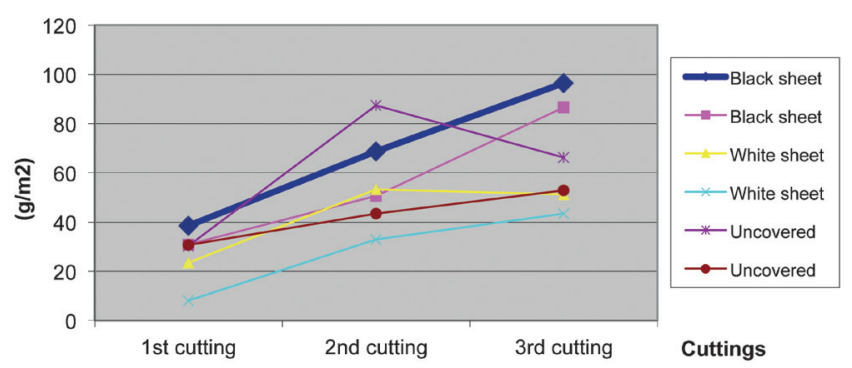

Figure 5. Evaluation of dry weight $\left(\mathrm{g} / \mathrm{m}^{2}\right)$ by different cuttings and treatments
The health condition of the plants was the best on the black sheet covering plots. In contrast, in the control plots the fungi infection affected the health of the plants with a reduction of more than $30 \%$.

Evaluation of total raw leaf weight $\left(\mathrm{g} / \mathrm{m}^{2}\right)$ of cuttings (Figure 4) we can state that the higher yield was on the black sheet cover plots with low cutting treatment comparing to normal (upper one third) cutting. Thereby, the low cutting produced higher yield, which can be explained by its stimulating effect of plant renewing.

The dry leaf weight was highest by the black sheet covering with low cutting (Fig. 5), but the uncovered (control) treatment was rather good until second cutting time (13 of August). This favourable condition could be continue until the end of vegetation but the increased fungi infection disturbed it. Probably, this problem could be eliminate partially with reasonable water supply.

\section{Conclusions}

According to our results about stevia production, is recommended the use of black plastic sheet covering or other mulch material (bark and chippings or compost). They can assure balanced water humidity in the root zone and weed control. In our circumstances, the stevia production is possible just with irrigation, to assure until $50 \%$ of water capacity. For water supply, drip irrigation is better than sprinkler one, because it can moderate the fungi infection of leaves. On the uncovered surface, it is important to avoid the excess soil moisture. In the first harvest time, the lower cutting is better because it improves the side branches which can propose higher yield at the following cuttings. It is important to choose the proper cutting time, because the cooler and humid climate is more favourable for renewing the plantation. On the other hand, the lower cutting during the warm summer days are not recommended because the reduced assimilation surface will put high stress on the plants.

The profitability of stevia production can be improved with increasing the number of cuttings. So the transplantation could be started at the end of April when the soil temperature is at least $10-12{ }^{\circ} \mathrm{C}$. Thereby the first cutting could be started at the beginning of July, when the process would be only picking the plants at $15-20 \mathrm{~cm}$ high to improve the side branches. After that, it is possible to cut every 5 or 6 weeks depending on the growing intensity (better nutrition supply and more favourable climatic conditions).

Differently from other cultivation, stevia is very slow to establish. The starting improvement is very slow until July. The main part of leaf yield will be improved after that time, until September.

After harvesting, the fresh biomass should be put on sunshine protected place, if not, quality and colour intensity of the dried leaves will be decreased.

To summarize, the results of the experiment have shown that stevia production can be performed in Hungary. 


\section{References}

Bondarev, N. I., Sukhanova, M. A., Semenova, G. A., Goryaeva, O. V., Andreeva, S. E., Nosov, A. M. (2010): "Morphology and ultrastructure of Trichomes of Intact and In vitro plants of Stevia rebaudiana Bertoni with reference to biosynthesis and accumulation of steviol glycosides",Moscow Univ. Sci. Bull., Vol. 65, pp. 12-16.

Carneiro, J. W. P. (2007): "Stevia rebaudiana (Bert.) Bertoni: Stages of plant development”, Can. J. Plant Sci., Vol. 87, pp. 861865.

Geuns, J. M. C., Augustijns, P., Mols, R., Buyse, J. G., Driessen, B. (2003): Metabolism of stevioside in pigs and intestinal absorption characteristics of stevioside, rebaudioside A and steviol. Food and Chem. Toxicology 41. 1599-1607.

Jain, P., Kachhwaha, S., Kothari, S. L. (2014): Biotechnology and metabolic engineering of Stevia rebaudiana (bert.) Bertoni: perspective and possibilities. Int. J. LifeSc. Bt \& Pharm. Res. Vol. 3, No. 3, 17-37.

Kinghorn, A. D., Nanayakkara, N. R. D., Soejarto, D. D., Medon, R. J. (1982): Potential sweetening agents of plant origin I. Purification of Stevia rebaudiana sweet constituents by droplet counter-current chromatography. J. Chromatogr., 2(37): 478-483.
Metivier, J. \& Viana, A. M. (1979): "The effect of long and short day length upon the growth of whole plants and the level of soluble proteins, sugars and stevioside in leaves of Stevia rebaudiana", Bert. J. Exp. Bot., Vol. 30, pp. 1211-1222.

Reeleder, R. (1999): Septoria Leaf Spot of Stevia rebaudiana in Canada and Methods for Screening for Resistance. Journal of Phytopathology. 147: 605-613.

Shizhen, S. (1995): "A study on good variety selection in Stevia rebaudiana”. Sci. Agric. Sin., Vol. 28, pp. 37-41.

Soejaro, D. D., Kinghorn, A. D., Farmswoth, N. R. (1982): Potential sweetening agens of plant origin III Organoleptic evaluation of Stevia leaf herbarium samples for sweetness. Journal of Natural Products. 45. 590-599.

Surjit, S., Gunjan. B., Kumar B. S., Krishnendu, A. (2012): Management of leaf spot disease of 'Stevia rebaudiana' Bertoni with antagonistic bacteria. Australian Journal of Crop Science. Volume 6 Issue 2. 350-356.

Swithers, S. E., \& Davidson, T. L. (2008): A role for sweet taste. Calorie predictive relations in energy regulation by rats. Behavioral Neuroscience. 122. 161-173.

Yamada, A., Ohgaki, S., Noda, T., Shimizu, M. (1985): Chronic toxicity study of dietary stevia extracts in F344 rats. Shokuhin Eiseigaku Zasshi, 26. 169-183. 